EGU2020-10038

https://doi.org/10.5194/egusphere-egu2020-10038

EGU General Assembly 2020

(c) Author(s) 2021. This work is distributed under

the Creative Commons Attribution 4.0 License.

\title{
Dynamic Real-time Hydrological Status Monitoring in the UK
}

\author{
Lucy Barker ${ }^{1}$, Gemma Nash ${ }^{2}$, Matt Fry' ${ }^{1}$ Jamie Hannaford ${ }^{1,3}$, and Maliko Tanguy ${ }^{1}$ \\ ${ }^{1}$ UK Centre for Ecology \& Hydrology, Crowmarsh Gifford, Wallingford, United Kingdom of Great Britain and Northern \\ Ireland (lucybar@ceh.ac.uk) \\ ${ }^{2}$ UK Centre for Ecology \& Hydrology, Edinburgh, United Kingdom of Great Britain and Northern Ireland \\ ${ }^{3}$ Irish Climate Analysis and Research UnitS (ICARUS), Maynooth University, Maynooth, Ireland
}

Understanding the current hydro-meteorological situation is critical to manage extreme events and water resources. The UK Water Resources Portal (UKWRP) has been developed to enable dynamic, interactive, real-time access to hydro-meteorological data, including catchment daily rainfall, real-time daily mean river flows, real-time soil moisture data from COSMOS-UK and standardised climate indices. Users can access and view data at the field, grid cell and catchment scale enabling holistic assessments of the hydro-meteorological status at a range of spatial scales. The portal offers a way of exploring the full range of river flow and rainfall variability, including comparing current conditions to those in the past, from droughts to floods. A variety of different plotting capabilities mean users can view and explore data in different ways depending on their requirements.

The UKWRP can be used alone or alongside other resources such as: the UK Hydrological Outlook seasonal forecasts, the Hydrological Summary for the UK and Environment Agency Water Situation Reports, to manage water resources, to plan and prepare for extreme events, and to understand and communicate their severity. The UKWRP enables all water users, from farmers, to water companies to members of the general public to view and explore the data used by regulators to manage water supplies. Equalising access to data can be extremely powerful; for example in the case of farmers, it means they can easily view real time river flows in relation to conditions on their licence using the same data used by regulators to impose abstraction restrictions during a drought.

Here we present the stakeholder engagement story of how and why the UKWRP was developed, demonstrate the capability of the UKWRP to monitor the hydrological situation in real time, and present plans for its future development, such as the addition of more indicators and indices. 